\title{
EXPOSURE TO EXCESSIVE SOUNDS AND HEARING STATUS IN ACADEMIC CLASSICAL MUSIC STUDENTS
}

\author{
MAŁGORZATA PAWLACZYK-ŁUSZCZYŃSKA, MAŁGORZATA ZAMOJSKA-DANISZEWSKA, \\ ADAM DUDAREWICZ, and KAMIL ZABOROWSKI
}

Nofer Institute of Occupational Medicine, Łódź, Poland

Department of Physical Hazards

\begin{abstract}
Objectives: The aim of this study was to assess hearing of music students in relation to their exposure to excessive sounds. Material and Methods: Standard pure-tone audiometry (PTA) was performed in 168 music students, aged $22.5 \pm 2.5$ years. The control group included 67 subjects, non-music students and non-musicians, aged $22.8 \pm 3.3$ years. Data on the study subjects' musical experience, instruments in use, time of weekly practice and additional risk factors for noise-induced hearing loss (NIHL) were identified by means of a questionnaire survey. Sound pressure levels produced by various groups of instruments during solo and group playing were also measured and analyzed. The music students' audiometric hearing threshold levels (HTLs) were compared with the theoretical predictions calculated according to the International Organization for Standardization standard ISO 1999:2013. Results: It was estimated that the music students were exposed for $27.1 \pm 14.3 \mathrm{~h} /$ week to sounds at the A-weighted equivalent-continuous sound pressure level of $89.9 \pm 6.0 \mathrm{~dB}$. There were no significant differences in HTLs between the music students and the control group in the frequency range of 4000-8000 Hz. Furthermore, in each group HTLs in the frequency range $1000-8000 \mathrm{~Hz}$ did not exceed $20 \mathrm{~dB}$ HL in $83 \%$ of the examined ears. Nevertheless, high frequency notched audiograms typical of the noise-induced hearing loss were found in $13.4 \%$ and $9 \%$ of the musicians and non-musicians, respectively. The odds ratio (OR) of notching in the music students increased significantly along with higher sound pressure levels $(\mathrm{OR}=1.07,95 \%$ confidence interval $(\mathrm{CI}): 1.014-1.13, \mathrm{p}<0.05)$. The students' HTLs were worse (higher) than those of a highly screened non-noise-exposed population. Moreover, their hearing loss was less severe than that expected from sound exposure for frequencies of $3000 \mathrm{~Hz}$ and $4000 \mathrm{~Hz}$, and it was more severe in the case of frequency of $6000 \mathrm{~Hz}$. Conclusions: The results confirm the need for further studies and development of a hearing conservation program for music students. Int J Occup Med Environ Health 2017;30(1):55-75
\end{abstract}

Key words:

Noise-induced hearing loss, Music students, Exposure to excessive sounds, Pure-tone audiometry,

Hearing threshold levels, High-frequency notches

\section{INTRODUCTION}

Noise-induced hearing loss (NIHL) is the second most prevalent sensorineural hearing loss, preceded only by presbyacusis. The potential risk of hearing loss in musicians has been extensively investigated since 1960 s.
The majority of studies have focused on professional musicians, people working in music venues and general public listening to loud music for a long time.

It has been shown that players, especially professional orchestral musicians, can develop NIHL and suffer from other

Funding: the study was supported by the Ministry of Science and Higher Education of Poland grant IMP 18.2/2012-2013 "Assessment of exposure to excessive sounds and hearing status in students enrolled in academic music education." Grant manager: Małgorzata Pawlaczyk-Łuszczyńska, Ph.D. with habilitation, NIOM professor. Received: June 12, 2015. Accepted: January 4, 2016.

Corresponding author: M. Pawlaczyk-Łuszczyńska, Nofer Institute of Occupational Medicine, Department of Physical Hazards, św. Teresy 8, 91-348 Łódź, Poland (e-mail: Malgorzata.Pawlaczyk@imp.lodz.pl). 
hearing symptoms such as tinnitus or hyperacusis, which can influence their work abilities more severely than the hearing loss itself. However, because of insufficient audiometric evidence of hearing loss caused purely by music exposure, there is still disagreement and speculation concerning the risk of hearing loss from music exposure alone [1-10].

According to the literature data, musicians, in particular classical orchestral musicians, are often exposed to sounds at levels exceeding the upper exposure action values from the Noise Directive 2003/10/EC [11] as well as the Polish maximum admissible intensity (MAI) values [12]. College music students are potential future employees of orchestras, so they constitute a group at a higher risk of hearing loss. However, data on noise exposure conditions and hearing status in college music students are limited. What is more, music students are not covered by the same regulatory framework as employees.

For example, Phillips and Mace [13] have measured sound pressure levels (SPLs) among students of a University School of Music in USA and found that singers and brass, wind and string players during individual music classes were exposed to sounds at averaged A-weighted SPLs of $87-95 \mathrm{~dB}$. Such levels are comparable to those measured in professional orchestral musicians [14-17]. Furthermore, Fearn [18] has estimated that students spent on average $10-35 \mathrm{~h} /$ week on playing musical instruments and additionally performed in orchestras for 2-3 h 56 times/year. For comparison, Pawlaczyk-Łuszczyńska et al. [10] have found that professional orchestral musicians were usually exposed to music for 7-70 h/week (average $30 \mathrm{~h} /$ week) due to both on-the-job and off-the-job playing. Therefore, it is not surprising that Phillips et al. [19], when analyzing the prevalence of hearing impairment in student musicians (aged 18-25 years), have found typical NIHL notches (occurring mainly at $6000 \mathrm{~Hz}$ ) in $45 \%$ of 329 students.

On the other hand, in Barlow's study [20], 44\% of 50 young people studying popular music showed evidence of audiometric notch at $4000-6000 \mathrm{~Hz}$, and $16 \%$ were classified under the UK Occupational Health and Safety guidelines as exhibiting mild hearing loss. The prevalence of notched audiograms was considerably higher than the one reported by the studies on the general population but was around the same level or lower than that reported from the studies of "traditional" music courses and conservatoires.

Furthermore, students exposed to music at high sound pressure levels were found to have moderate temporary threshold shifts, which correlated with their history of personal exposure, most significantly at $4000 \mathrm{~Hz}$. Moreover, transient-evoked otoacoustic emission (TEOAE) responses in those young musicians showed overall lower amplitudes compared to the students with less exposure to music [21]. The overall objective of this study was to analyze hearing status of undergraduate music students in relation to their exposure to sounds during university education. In particular, it has been attempted to:

- evaluate the total sound exposure of music students, including their various activities associated with playing instruments, and on that basis, to determine the expected noise-induced permanent threshold shifts, according to the model described in the International Organization for Standardization standard ISO 1999:2013 [22];

- compare audiometric hearing thresholds in the music students to the age-related reference data from the otologically normal population ("highly screened") in accordance with ISO 7029:2000 [23], that is database A from ISO 1999:2013, as well as to the unscreened, agedrelated normal control group comprising young people who were non-music students and non-musicians;

- analyze the association between music exposure and some hearing symptoms, including the presence of high frequency notched audiograms and tinnitus.

\section{MATERIAL AND METHODS}

Exposure to excessive sounds and audiometric hearing threshold levels were determined in university music students. Data on the students' musical experience, 
instruments in use, time of weekly practice and additional risk factors for noise-induced hearing loss were identified by means of a questionnaire survey. In addition, their hearing ability was assessed using the (modified) Amsterdam Inventory for Auditory Disability and Handicap ((m)AIADH) [24]. Audiometric hearing threshold levels (HTLs) were compared with the theoretical predictions calculated according to ISO 1999:2013 [22].

The study comprised 168 undergraduate classical music students, aged 19.3-31.7 years from 2 universities, i.e., Academy of Music in Lódź and Academy of Music in Gdańsk, Poland. The comparison group consisted of 67 subjects, aged 18-31 years, who were non-music students and non-musicians and who were not exposed to noise at work. In both groups, individuals with middle ear pathology were excluded from the study.

The subjects received financial compensation for their participation in the study. They were recruited by advertisement. The study protocol was approved by the Ethic Committee of the Nofer Institute of Occupational Medicine, Łódź, Poland (decision No. 8/2013) and all the subjects gave their written informed consent for participation in the examinations.

\section{Questionnaire survey}

All the music students filled in a questionnaire developed to enable identification of risk factors for NIHL. In particular, the questionnaire included items related to:

- music exposure (i.e., years in school (playing instruments), instruments played, hours of individual and group practice per day/week currently/in the past, ensemble participation),

- health status and medical history (past middle-ear diseases, and surgery, etc.),

- physical features (body weight, height, skin pigmentation),

- lifestyle (smoking, noisy hobbies, listening to personal media player, attending disco/bars, rock concerts, etc.),
- use of individual hearing protectors,

- self-assessment of hearing status.

The subjects from the control group were also interviewed using a similar questionnaire, but without questions on music exposure.

In addition, all the subjects completed a (modified) Amsterdam Inventory for Auditory Disability and Handicap. This questionnaire consists of 30 questions, including 2 control questions not included in the assessment. The questions are divided into 5 parts (subscales) separately assessing:

- ability of discrimination (differentiation) of sounds (subscale I),

- auditory localization (subscale II),

- understanding speech in noise (subscale III),

- intelligibility in quiet (subscale IV),

- detection of sounds (subscale V).

The respondents reported how often they were able to hear effectively in the situations specified above. The 4 answer categories were as follows: almost never, occasionally, frequently and almost always. Responses to each question were coded on a scale from 0 to 3 ; the higher the score, the smaller the perceived hearing difficulties. The total score per subject was obtained by adding the scores for 28 questions. Maximum total score for the questionnaire was 84 . Additionally, the answers for each subscale were summed up (maximum score for subscale I was 24 , while for other subscales the total was 15) [24].

\section{Hearing examinations}

The standard pure-tone audiometry (PTA) was performed, using the Audio Traveller Audiometer type 222 (Interacoustics, USA) with TDH 39 headphones. Hearing threshold levels (HTLs) for air conduction at frequencies $250-8000 \mathrm{~Hz}$ were determined using the ascending-descending technique in 5-dB steps. In addition, transient-evoked otoacoustic emissions (TEOAE) and 
distortion-product otoacoustic emissions (DPOAE) were determined. However, results of the latter tests will be described elsewhere.

Before the hearing tests, otoscopy was performed in order to screen for conditions that would exclude an examined subject from the study. The hearing examinations were carried out in a sound-proof room or in quiet rooms located in universities' buildings where the A-weighted equivalent-continuous sound pressure level of background noise did not exceed $35 \mathrm{~dB}$.

\section{Music exposure evaluation}

To evaluate the students' exposure to music (excessive sounds), sound pressure level (SPL) was measured during individual and collective rehearsals as well as during lessons with a teacher and concerts. The surveys included various instruments and diverse repertoire. The measurements were performed according to the Polish standards PN-N-01307:1994 and PNEN ISO 9612:2011 (ISO 9612:2009) [25-27] using personal sound exposure meters (i.e., personal logging dosimeters type 4436 and 4443 (Brüel \& Kjær, Denmark)) worn by the students playing instruments. The distance between the microphone and the ears $(0.1-0.4 \mathrm{~m})$ was as short as practically possible (without disturbing the players). Each single measurement period usually corresponded to the duration of a rehearsal, lesson or a concert. In general, results of 294 measurement samples (covering in total approx. $231 \mathrm{~h}$ ) were collected.

For each study subject, the A-weighted weekly noise exposure level $\left(\mathrm{L}_{\mathrm{EX}, \mathrm{w}}\right)$ was calculated from the values of the A-weighted equivalent-continuous sound pressure levels produced by the respective instrument (e.g., violin or trumpet) and time of weekly practice obtained from the questionnaire, using the following equation (1):

$$
\mathrm{L}_{\mathrm{EX}, \mathrm{w}}=10 \times \log \left[\frac{1}{\mathrm{~T}_{\mathrm{o}}} \times\left(\mathrm{T}_{1} \times 10^{0.1 \times \mathrm{L}_{\text {Aeq, T1 }}}+\mathrm{T}_{2} \times 10^{0.1 \times \mathrm{L}_{\text {Aeq } \mathrm{T} 2}}\right)\right]
$$

where:

$\mathrm{L}_{\text {Aeq, T1 }}$ - the energy average of collected samples of the A-weighted equivalent-continuous SPL produced by respective instrument during collective playing, in $\mathrm{dB}$,

$\mathrm{L}_{\text {Aeq,T2 }}$ - the energy average of collected samples of the A-weighted equivalent-continuous SPL produced by respective instrument during individual playing, in $\mathrm{dB}$,

$\mathrm{T}_{1}, \mathrm{~T}_{2}$ - the declared time of collective and individual practice per week, in hours,

$\mathrm{T}_{\mathrm{o}}$ - the reference duration equalled $40 \mathrm{~h}$.

Additionally, the students' exposures were described by a noise immission level $\left(\mathrm{L}_{\mathrm{IM}}\right)$, i.e., a measure of the cumulative sound (noise) energy to which an individual was exposed over time given by the formula (2):

$$
\mathrm{L}_{\mathrm{IM}}=\mathrm{L}_{\mathrm{EX}, \mathrm{W}}+10 \times \log \mathrm{T}
$$

where:

$\mathrm{L}_{\mathrm{EX}, \mathrm{w}}-\mathrm{A}$-weighted weekly noise exposure level, in $\mathrm{dB}$,

$\mathrm{T}$ - time of exposure to excessive sounds (playing instrument) after age of 18 years, in years.

\section{Prediction of noise-induced hearing loss}

The music students' audiometric hearing threshold levels were compared with the theoretical predictions calculated in accordance with ISO 1999:2013 [22]. The aforesaid standard specifies the method for determining statistical distribution of hearing threshold levels in adult populations after exposure to noise based on 4 parameters: age, gender, noise exposure level (i.e., A-weighted equivalent continuous SPL normalized over a 8-h working day or a 40-h working week) and time (duration) of noise exposure (in years).

However, to compare predictions obtained for the students of different gender, age, time and exposure, the socalled standardized hearing threshold levels (SHTL) were determined using the following formulas (3) and (4): 


$$
\begin{aligned}
& \mathrm{SHTL}=1.282 \times\left(\mathrm{HTL}_{\mathrm{P}} \mathrm{PHTL}_{\mathrm{Q} 50}\right) / \\
& \left(\mathrm{PHTL}_{\mathrm{Q} 10}-\mathrm{PHTL}_{\mathrm{Q} 50}\right) \text { for } \mathrm{HTL} \geq \mathrm{PHTL}_{\mathrm{Q} 50}
\end{aligned}
$$

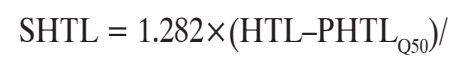

$$
\begin{aligned}
& \left(\mathrm{PHTL}_{\mathrm{Q} 90}-\mathrm{PHTL}_{\mathrm{Q} 50}\right) \text { for HTL }<\mathrm{PHTL}_{\mathrm{Q} 50}
\end{aligned}
$$

where:

HTL - the actual hearing threshold level, in dB HL, $\mathrm{PHTL}_{\mathrm{Q} 50 / \mathrm{Q} 10 / \mathrm{Q} 90}-$ median, 10th and 90th percentiles of predicted distribution of hearing threshold level 1, in $\mathrm{dB}$ HL.

These calculations were applied to the students' audiograms twice, i.e., their HTLs were compared to the HTLs of the highly screened (otologically normal) non-noiseexposed population (database A from ISO 1999:2013) and an equivalent (according to age, gender, $\mathrm{L}_{\mathrm{EX}, \mathrm{w}}$ and $\mathrm{T}$ ) noise-exposed population.

Standardized hearing threshold levels were also determined for the control group. However, in the latter case, audiograms were only related to the data from otologically normal persons not occupationally exposed to noise.

\section{Statistical analysis}

Differences in variables averages between subgroups of the study subjects (i.e., the music students and control group as well as between the stringed, wind and percussion instrument players) were analyzed using the t-test for independent data or the Mann-Whitney U test, where applicable.

The relations between HTLs and sound exposure parameters were evaluated using the Spearman's rank correlation coefficient. The standardized hearing threshold levels were analyzed using the one-sample t-test.

Answers to the questionnaire and frequency of some outcomes (e.g., prevalence of the high-frequency notched audiograms) were presented as proportions with $95 \%$ confidence intervals $(95 \% \mathrm{CI})$. Differences in proportions between various pairs of the subgroups (e.g., the music students and control group or various instruments players) were analyzed using the Fisher's exact test.

The binary logistic regression with Wald test was used for the analysis of association between the prevalence of hearing-related outcomes (e.g., high-frequency notched audiograms) and sound exposure level, age, gender, time of playing instrument and other factors.

Statistical analysis was carried out with an assumed level of significance $p=0.05$. However, when comparing pairs of various subgroups of the subjects, to avoid the risk of mass significance, a $\mathrm{p}$-value divided by the number $(\mathrm{N})$ of possible comparisons $(\mathrm{p}=0.05 / \mathrm{N})$ was set as a limit for statistical significance. The statistical analysis employed Statistica (version 9.1.) (StatSoft, Inc., USA) software package.

\section{RESULTS}

\section{The study groups characteristics and questionnaire data}

Among 168 music students, $60.1 \%$ played stringed instruments, $33.3 \%$ played wind instruments and $6.5 \%$ played percussion (Figure 1). Their mean (M) age was 22.8 years (with standard deviation (SD) of 2.5 years, median (Me) of 22.4 years). Regarding gender, $48.8 \%$ (82) of them were female students and $51.2 \%$ (86) were male students. Time of musical practice varied from 6 to 20 years $(\mathrm{M} \pm \mathrm{SD}=12.5 \pm 3.2$ years, $\mathrm{Me}=13$ years $)$. Several students played more than one musical instruments.

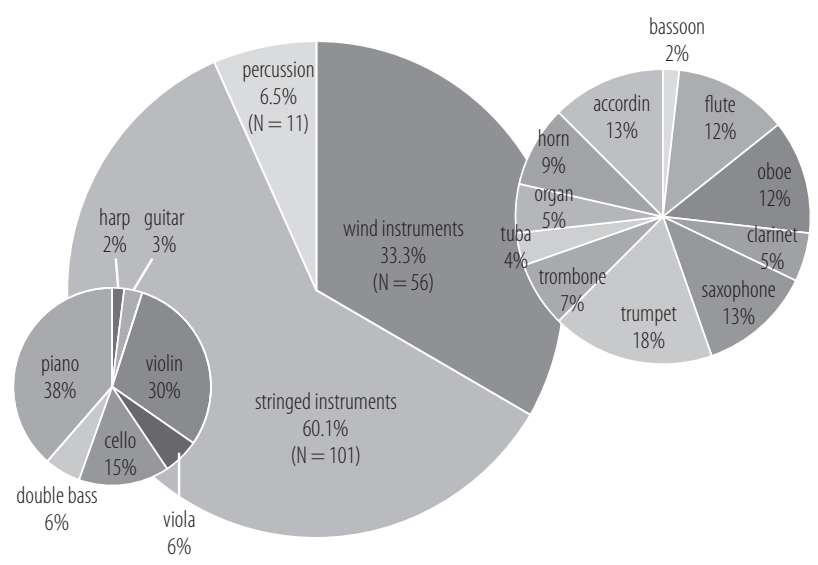

Fig. 1. Students playing various instruments 
Majority (85.4\%) of the 67 subjects from the control group were non-music students. About one-quarter (25.4\%) of them were occasionally exposed to noise at their workplace or during internship or apprenticeship.

In the control group, the mean age was also 22.8 years ( $\mathrm{SD}=3.3$ years, $\mathrm{Me}=22.3$ years $)$. In terms of gender, women were a little more numerous than men (56.2\% vs. $44.8 \%)$. However, in general, there were no significant differences concerning age and gender between the music students and controls. Similar relationships were observed when analyzing medical history, physical features and some aspects of lifestyle, such as: smoking habits and noisy hobbies (shooting, paintball, motor sports, etc.) (Tables 1 and 2). However, greater fractions of the music students compared to the control group reported listening to personal media play-

Table 1. Prevalence of noisy hobbies in the music students and in the control group

\begin{tabular}{|c|c|c|}
\hline \multirow[t]{2}{*}{ Noisy hobby } & \multicolumn{2}{|c|}{$\begin{array}{c}\text { Respondents } \\
{[\%(95 \% \mathrm{CI})]}\end{array}$} \\
\hline & music students & control group \\
\hline Listening to PMPs & $86.9(80.9-91.2)$ & $77.6(66.10-86.00)$ \\
\hline \multicolumn{3}{|l|}{ Using PMPs } \\
\hline at least $1 \mathrm{~h}$ daily & $62.5(55.0-69.5)^{*}$ & $40.3(29.40-52.30)^{*}$ \\
\hline every day & $57.1(49.6-64.4)^{*}$ & $35.8(25.40-47.80)^{*}$ \\
\hline \multicolumn{3}{|l|}{ Frequent attending clubs, pubs, etc. } \\
\hline never & $7.1(4.1-12.2)$ & $6.0(2.00-14.90)$ \\
\hline nowadays & $12.5(8.3-18.5)$ & $4.5(1.10-13.00)$ \\
\hline in the past & $11.9(7.8-17.8)^{*}$ & $1.5(0.01-8.80)^{*}$ \\
\hline \multicolumn{3}{|c|}{ Frequent attendance at loud music concerts, etc. } \\
\hline never & $14.3(9.8-20.5)$ & $20.9(12.80-32.30)$ \\
\hline nowadays & $4.8(2.3-9.3)$ & $1.5(0.01-8.80)$ \\
\hline in the past & $4.8(2.3-9.3)$ & $1.5(0.01-8.80)$ \\
\hline \multicolumn{3}{|l|}{ Practicing noisy motor sports (quads) } \\
\hline never & $80.4(73.6-85.7)$ & $76.1(64.50-84.80)$ \\
\hline nowadays & $13.1(8.8-19.1)$ & $16.4(9.30-27.30)$ \\
\hline in the past & $6.0(3.2-10.8)$ & $6.0(2.00-14.90)$ \\
\hline \multicolumn{3}{|l|}{ Shooting } \\
\hline never & $81.5(74.9-86.7)$ & $70.1(58.30-79.80)$ \\
\hline nowadays & $14.3(9.8-20.5)$ & $22.4(14.00-33.90)$ \\
\hline in the past & $4.2(1.9-8.6)$ & $6.0(2.00-14.90)$ \\
\hline \multicolumn{3}{|l|}{ Using noisy tools } \\
\hline never & $44.6(37.3-52.2)$ & $43.3(32.10-55.20)$ \\
\hline nowadays & $26.8(20.7-34.0)^{*}$ & $11.9(6.00-22.20)^{*}$ \\
\hline in the past & $28.0(21.7-35.2)^{*}$ & $41.8(30.80-53.70) *$ \\
\hline
\end{tabular}

PMPs - personal media players; $\mathrm{CI}$ - confidence interval.

* Significant differences $(\mathrm{p}<0.05)$. 
Table 2. Prevalence of risk factors other than noise exposure for the noise-induced hearing loss (NIHL) in the music students and in the control group

\begin{tabular}{lcc}
\hline & \multicolumn{2}{c}{ Respondents } \\
& \multicolumn{2}{c}{ Risk factor $(95 \% \mathrm{CI})]$} \\
\hline Smoking & music students & control group \\
$\quad$ nowadays & $35.7(28.90-43.20)$ & $32.8(22.8-44.8)$ \\
$\quad$ in the past & $38.1(31.10-45.60)$ & $25.4(16.5-37.1)$ \\
Elevated blood pressure & $3.6(1.50-7.80)$ & $4.5(1.1-13.0)$ \\
Diabetes & $0.6(0.01-3.60)$ & $0.0(0.0-6.7)$ \\
Raynaud's phenomenon & $3.0(1.10-7.00)$ & $3.0(0.3-11.0)$ \\
Light skin pigmentation & $28.0(21.70-35.20)$ & $23.9(15.2-35.5)$ \\
Ototoxic antibiotic treatment & $5.4(2.70-10.10)$ & $7.5(2.9-16.8)$ \\
Body mass index $($ BMI $)>25$ & $20.2(14.90-27.00)$ & $26.9(17.7-38.6)$ \\
\hline
\end{tabular}

CI - confidence interval.

ers (PMPs) (for at least an hour) every day $(57.1 \%$ vs. $35.8 \%, p<0.05)$ and frequent attending music clubs in the past $(11.9 \%$ vs. $1.5 \%, \mathrm{p}<0.05)$. On the other hand, subjects in the control group declared frequent use of noisy tools in the past more often than the music students $(41.8 \%$ vs. $28 \%, \mathrm{p}<0.05)$, while the opposite relation was observed nowadays $(11.9 \%$ vs. $26.8 \%$, $\mathrm{p}<0.05)$ (Table 1).

It is worth noting that only $8.9 \%$ (95\% CI: $5.4-14.3 \%$ ) of the music students declared using hearing protective devices (mainly earplugs) at present or in the past, while $47 \%$ (95\% CI: 39.6-54.6\%) players intended to use them in the future. Hearing protective devices were mainly worn during rehearsals, including group rehearsals (27.9\%) and solo rehearsals at school (18.6\%) and at home (16.3\%).

Regarding the prevalence of other NIHL risk factors such as: smoking, elevated blood pressure, diabetes, white-finger syndrome, light skin pigmentation, ototoxic antibiotic treatments and overweight (body mass index $(\mathrm{BMI})>25$ ), there were no significant differences between the study subjects and the comparative group (Table 2).

\section{Assessment of exposure to music}

Table 3 summarizes sound pressure levels measured in the students playing different instruments during solo and group rehearsals, lessons and concerts. According to the collected data, the music students were exposed to sounds at:

- the equivalent continuous A-weighted $\mathrm{SPL}\left(\mathrm{L}_{\text {Aeq, } \mathrm{T}}\right)$ of $80-98 \mathrm{~dB}(10-90$ th percentile),

- maximum A-weighted SPL $\left(\mathrm{L}_{\mathrm{Amax}}\right)$ of $94-113 \mathrm{~dB}$,

- peak C-weighted SPL $\left(\mathrm{L}_{\text {Cpeak }}\right)$ of $115-137 \mathrm{~dB}$.

There was a considerable diversity in sound exposure among the music students playing various instruments, partly due to the variability in the repertoire, kind of lessons and place of testing, etc. The highest $\mathrm{L}_{\text {Aeq, } \mathrm{T}}$ levels were measured among the percussion, brass instruments (saxophone, trumpet, trombone, tube, horn) and wood-wind (bassoon, flute, oboe, clarinet) players (Figure 2).

According to the responses included in the questionnaire, the music students played instruments on average for $27.1 \pm 14.3 \mathrm{~h} /$ week, including $16.4 \pm 8.2 \mathrm{~h}$ of solo practicing and $7.1 \pm 6.1 \mathrm{~h}$ of group playing. 


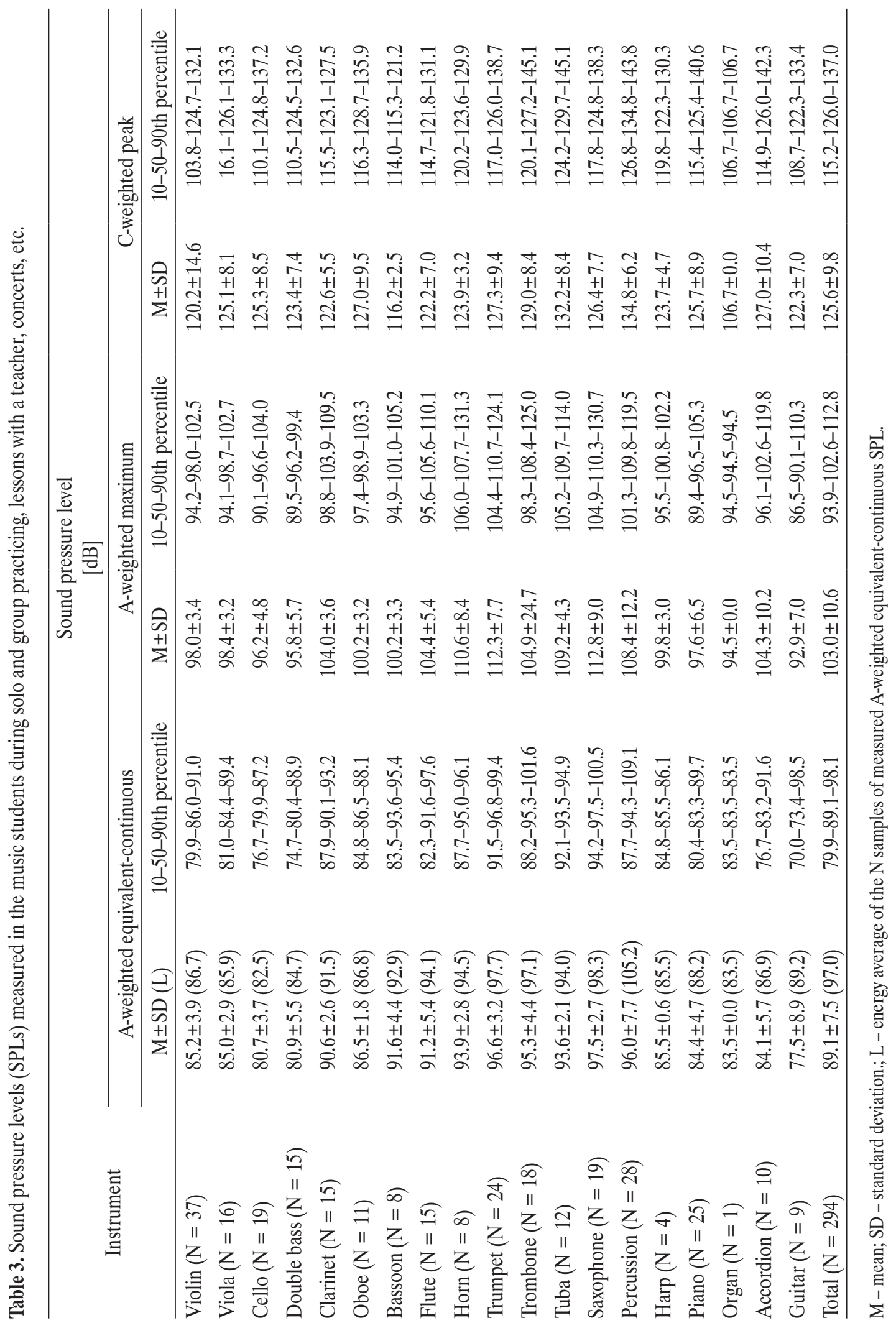




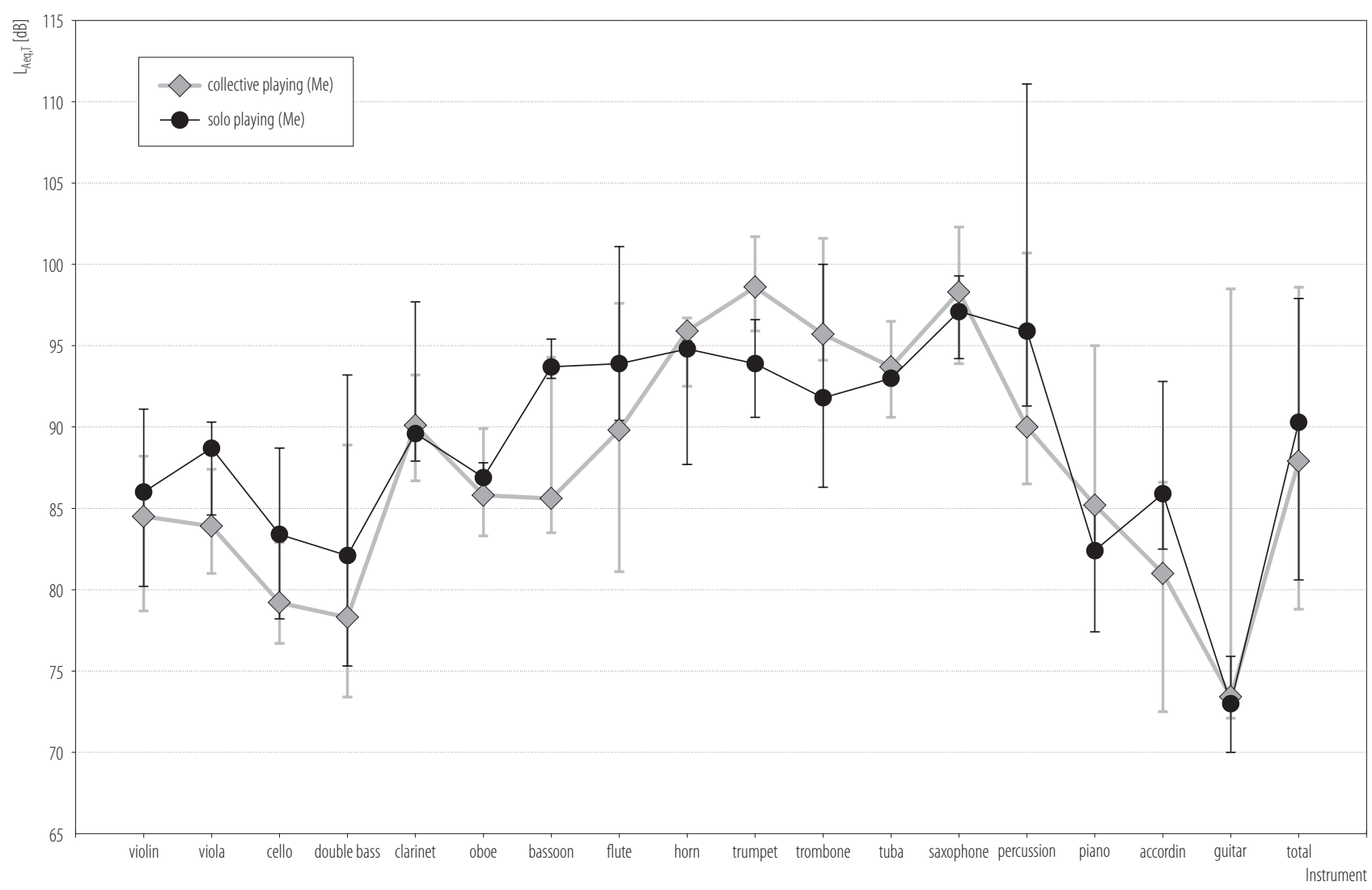

$\mathrm{L}_{\text {Aeq.T }}$ - A-weighted equivalent-continuous sound pressure level; Me - median.

Whiskers - range 10-90th percentile.

Fig. 2. A-weighted equivalent-continuous sound pressure levels measured in the music students playing various instruments during solo and collective practice

For each subject, a weekly noise exposure level $\left(\mathrm{L}_{\mathrm{EX}, \mathrm{w}}\right)$ was determined from the equivalent-continuous Aweighted SPLs produced by the respective instrument and the declared time of weekly practice (equation 1). Since some students played many instruments, such evaluations were based on the data concerning the main instrument. The weekly noise exposure levels calculated from those data ranged between $75-106 \mathrm{~dB}(\mathrm{M} \pm \mathrm{SD}=86.8 \pm 6.3 \mathrm{~dB}$, $\mathrm{Me}=84.9 \mathrm{~dB}$ ) (Figure 3), while the corresponding noise immission levels varied from $85 \mathrm{~dB}$ to $114 \mathrm{~dB}$ $(\mathrm{M} \pm \mathrm{SD}=94.4 \pm 6.2 \mathrm{~dB}, \mathrm{Me}=92.6 \mathrm{~dB})$. There were significant differences in sound exposure between the students playing instruments belonging to different groups. The highest values of the $\mathrm{L}_{\mathrm{EX}, \mathrm{w}}$ levels were observed in

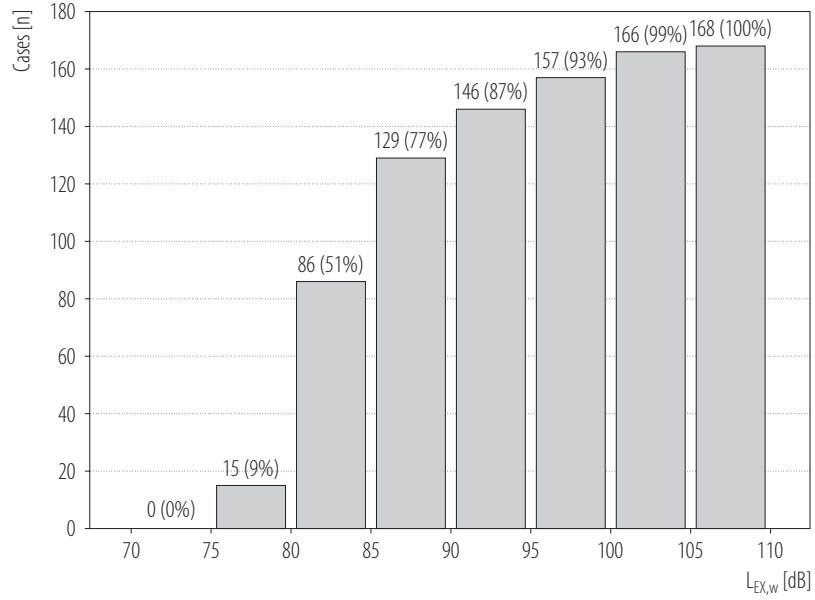

$\mathrm{L}_{\mathrm{EX}, \mathrm{w}}$ - A-weighted weekly noise exposure level.

Fig. 3. Cumulative distribution of the A-weighted weekly noise exposure level $\left(\mathrm{L}_{\mathrm{EX}, \mathrm{w}}\right)$ in the music students 


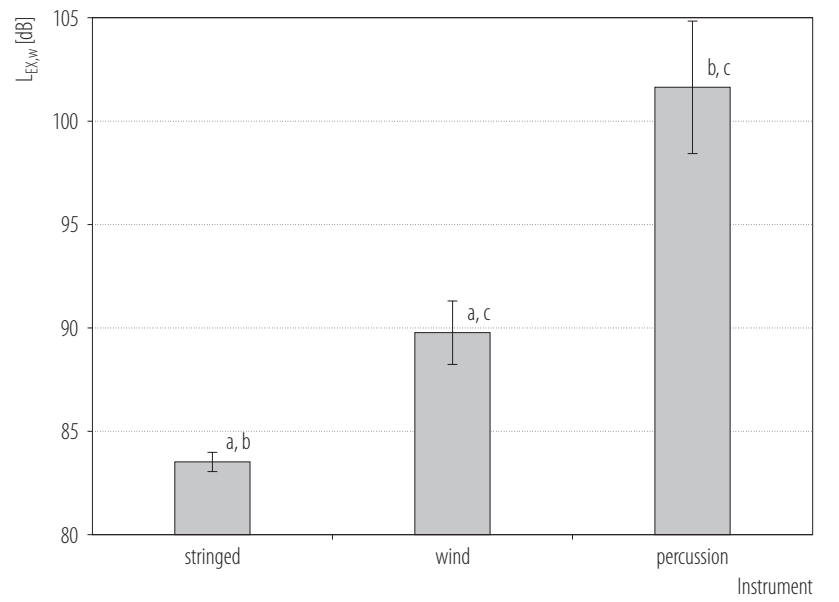

$\mathrm{L}_{\mathrm{EX}, \mathrm{w}}$ - A-weighted weekly noise exposure level.

a Significant differences between the stringed and wind instrument players $(\mathrm{p}<0.05 / 3)$.

${ }^{\mathrm{b}}$ Significant differences between the stringed and percussion instrument players $(\mathrm{p}<0.05 / 3)$.

c Significant differences between the wind and percussion instrument players $(\mathrm{p}<0.05 / 3)$.

Data are given as mean values with $95 \%$ confidence intervals.

Fig. 4. A-weighted weekly noise exposure levels $\left(\mathrm{L}_{\mathrm{EX}, \mathrm{w}}\right)$ in the music students playing stringed, wind and percussion instruments the students playing percussion, while the lowest in those playing stringed instruments (Figure 4).

Nearly half $(48.8 \%)$ of the students were exposed to excessive sounds at levels exceeding the Polish maximum admissible intensity (MAI) value for occupational noise $\left(\mathrm{L}_{\mathrm{EX}, \mathrm{w}}=85 \mathrm{~dB}\right)$ [12], while $29.2 \%$ of them were exposed to the $\mathrm{L}_{\mathrm{EX}, \mathrm{w}}$ levels above $87 \mathrm{~dB}$ (Figure 3), i.e., exposure limit value specified by the 2003/10/EC Directive [11].

\section{Self-assessment of hearing capability}

Generally, almost all the music students (92.9\%) and individuals in the control group (98.5\%) assessed their hearing as good. Nevertheless, some of them complained of various hearing-related symptoms (Table 4). In particular, greater proportions of the music students, compared to the control group, reported hearing impairment $(31.5 \%$ vs. $14.9 \%, \mathrm{p}<0.05)$ and complained of difficulty in speech intelligibility in a noisy environment (45.8\% vs. $29.9 \%$, $\mathrm{p}<0.05)$, constant or temporary tinnitus ( $11.3 \%$ vs. $4.5 \%$, $\mathrm{p}>0.05)$ and hyperacusis $(36.3 \%$ vs. $11.9 \%, \mathrm{p}<0.05)$.

Table 4. Prevalence of self-reported hearing-related symptoms in the music students and in the control group

\begin{tabular}{lcc}
\hline \multirow{2}{*}{ Symptom } & \multicolumn{2}{c}{$\begin{array}{c}\text { Respondents } \\
\text { [\% (95\% CI)] }\end{array}$} \\
\cline { 2 - 3 } Good hearing & music students & control group \\
Hearing impairment & $92.9(87.80-95.90)$ & $98.5(91.10-100.50)$ \\
self-reported & $31.5(25.00-38.90)^{*}$ & $14.9(8.20-25.60)^{*}$ \\
noticed by family & $8.9(5.40-14.30)$ & $10.4(4.90-20.40)$ \\
in the right ear & $3.6(1.50-7.80)$ & $1.5(0.01-8.80)$ \\
in the left ear & $9.5(5.90-15.00)$ & $4.5(1.10-13.00)$ \\
in both ears & $16.1(11.30-22.50)$ & $9.0(3.90-18.60)$ \\
sudden & $4.8(2.30-9.30)$ & $0.0(0.00-6.70)$ \\
increasing from year to year & $3.0(1.10-7.00)$ & $3.0(0.30-11.00)$ \\
increasing from month to month & $11.3(7.30-17.10)$ & $6.0(2.00-14.90)$ \\
increasing in different manner & $10.7(6.80-16.40)$ & $3.0(0.30-11.00)$ \\
Hearing loss in the family & $44.0(36.80-51.60)$ & $44.8(33.50-56.60)$ \\
\hline
\end{tabular}


Table 4. Prevalence of self-reported hearing-related symptoms in the music students and in the control group - cont.

\begin{tabular}{lcc}
\hline \multicolumn{1}{c}{ Symptom } & \multicolumn{2}{c}{$\begin{array}{c}\text { Respondents } \\
{[\%(95 \% \mathrm{CI})]}\end{array}$} \\
\cline { 2 - 3 } & \multicolumn{2}{c}{ music students } \\
\hline Difficulties with hearing/understanding & $9.5(5.90-15.00)^{*}$ & $19.4(11.60-30.60)^{*}$ \\
whisper & $2.4(0.70-6.20)$ & $1.5(0.01-8.80)$ \\
normal speech & $45.8(38.50-53.40)^{*}$ & $29.9(20.20-41.70)^{*}$ \\
speech in noisy environment & $0.6(0.01-3.60)$ & $0.0(0.00-6.70)$ \\
trebles & $13.7(9.30-19.80)$ & $7.5(2.90-16.80)$ \\
Use of higher radio and TV volume settings & $11.3(7.30-17.10)$ & $4.5(1.10-13.00)$ \\
Tinnitus & $2.4(0.70-6.20)$ & $3.0(0.30-11.00)$ \\
constant tinnitus & $8.9(5.40-14.30)$ & $4.5(1.10-13.00)$ \\
transient (periodic) tinnitus & $36.3(29.40-43.80)^{*}$ & $11.9(6.00-22.20)^{*}$ \\
Hyperacusis & & \\
\hline
\end{tabular}

$\mathrm{CI}$ - confidence interval.

* Significant differences $(\mathrm{p}<0.05)$.

The music students and non-music student controls examined using the (m)AIADH obtained the mean total score approximately $88 \pm 9 \%$ of the maximum value (84), which suggests no substantial hearing problems (Table 5). Moreover, significant differences neither in the total score nor in the scores in various subscales were noted between the aforesaid groups.
However, comparison of the (m)AIADH outcomes in various groups of players revealed that relatively low ( $<70 \%$ of maximum value) scores were most frequent in the percussion players (Table 6). In particular, significantly higher proportions of the students playing percussion than those playing stringed or wind instruments scored relatively low in subscale III (evaluating intelligibility in

Table 5. Hearing ability in terms of score in the (modified) Amsterdam Inventory for Auditory Disability and Handicap ((m)AIADH) in the music students and in the control group

\begin{tabular}{lcccc}
\hline \multirow{2}{*}{$(m)$ AIADH score } & \multicolumn{3}{c}{ Respondents } \\
\cline { 2 - 5 } & \multicolumn{2}{c}{ music students } & \multicolumn{2}{c}{ control group } \\
\cline { 2 - 5 } & $\mathrm{M} \pm$ SD & $10-50-90$ th percentile & M SD & $10-50-90$ th percentile \\
\hline Total & $73.7 \pm 7.2$ & $63-75-81$ & $73.8 \pm 7.3$ & $63-75.5-81$ \\
Subscale & & & & \\
I - Distinction of sounds & $21.9 \pm 2.0$ & $19-22-24$ & $21.9 \pm 2.1$ & $19-22-24$ \\
II - Auditory localization & $12.5 \pm 2.2$ & $9-13-15$ & $12.6 \pm 2.2$ & $9-13-15$ \\
III - Intelligibility in noise & $12.5 \pm 1.5$ & $11-12-14$ & $12.4 \pm 1.4$ & $11-12-14$ \\
IV - Intelligibility in quiet & $13.3 \pm 1.6$ & $11-14-15$ & $13.3 \pm 1.5$ & $11-14-15$ \\
V - Detection of sounds & $13.5 \pm 1.8$ & $11-14-15$ & $13.5 \pm 1.8$ & $11-14-15$ \\
\hline
\end{tabular}

Abbreviations as in Table 3. 
Table 6. Hearing ability in terms of scores below $70 \%$ of the maximum values in the (m)AIADH in the music students according to the played instrument

\begin{tabular}{lcccc}
\hline \multirow{2}{*}{ (m)AIADH score } & \multicolumn{4}{c}{$\begin{array}{c}\text { Respondents } \\
\text { [\% }(95 \% \text { CI })]\end{array}$} \\
\cline { 2 - 5 } & $\begin{array}{c}\text { music students } \\
\text { (total) }\end{array}$ & $\begin{array}{c}\text { stringed instrument } \\
\text { players }\end{array}$ & $\begin{array}{c}\text { wind instrument } \\
\text { players }\end{array}$ & $\begin{array}{c}\text { percussion } \\
\text { players }\end{array}$ \\
\hline Total $<70 \%$ & $3.1(1.2-7.2)$ & $1.0(0.01-5.90)^{\mathrm{a}}$ & $3.8(0.40-13.60)$ & $18.2(4.30-49.00)^{\mathrm{a}}$ \\
Subscale < 70\% & & & & \\
I - Distinction of sounds & $1.8(0.4-5.6)$ & $2.0(0.20-7.60)$ & $0.0(0.00-7.70)$ & $9.1(0.01-40.00)$ \\
II - Auditory localization & $17.8(12.7-24.5)$ & $16.2(10.10-24.80)$ & $15.1(7.70-27.40)$ & $45.5(21.40-71.90)$ \\
III - Intelligibility in noise & $6.7(3.7-11.8)$ & $6.1(2.60-12.90)^{\mathrm{a}}$ & $3.8(0.40-13.60)^{\mathrm{b}}$ & $27.3(9.50-57.20)^{\mathrm{a}, \mathrm{b}}$ \\
IV - Intelligibility in quiet & $5.5(2.8-10.3)$ & $5.1(1.90-11.70)^{\mathrm{a}}$ & $1.9(0.01-10.30)^{\mathrm{b}}$ & $27.3(9.50-57.20)^{\mathrm{a}, \mathrm{b}}$ \\
V - Detection of sounds & $6.7(3.7-11.8)$ & $4.0(1.30-10.30)^{\mathrm{a}}$ & $7.5(2.60-18.50)$ & $27.3(9.50-57.20)^{\mathrm{a}}$ \\
\hline
\end{tabular}

Abbreviations as in Tables 1 and 5.

${ }^{a}$ Significant differences between the percussion and stringed instrument players $(p<0.05 / 3)$.

${ }^{\mathrm{b}}$ Significant differences between the percussion and wind instrument players $(\mathrm{p}<0.05 / 3)$.

noise) and subscale IV (evaluating intelligibility in quiet) $(\mathrm{p}<0.05 / 3)$.

\section{Results of hearing tests}

Audiometric hearing threshold levels determined in the 168 music students (335 ears, one student had single sided deafness) and in 67 subjects (134 ears) from the control group are shown in Figure 5.

Majority of the study subjects had normal hearing (HTLs in the frequency range $1000-8000 \mathrm{~Hz} \leq 20 \mathrm{~dB} \mathrm{HL}$ ). Furthermore, both speech-frequency hearing loss (mean threshold at $500 \mathrm{~Hz}, 1000 \mathrm{~Hz}, 2000 \mathrm{~Hz}$ and $4000 \mathrm{~Hz}$ > $20 \mathrm{~dB} \mathrm{HL}$ ) and high-frequency hearing loss (mean threshold at $3000 \mathrm{~Hz}, 4000 \mathrm{~Hz}$ and $6000 \mathrm{~Hz}>20 \mathrm{~dB} \mathrm{HL}$ ) were observed only in a few percent of the analyzed audiograms (Table 7).

Nevertheless, typical NIHL notches at $4000 \mathrm{~Hz}$ or $6000 \mathrm{~Hz}$ of at least $15 \mathrm{~dB}$ depth (relative to both the best preceding threshold occurring at frequencies $1000-3000 \mathrm{~Hz}$ (or $1000-4000 \mathrm{~Hz}$ ) and the threshold at $8000 \mathrm{~Hz}$ ) were observed in $13.4 \%$ and $9 \%$ of audiograms in the music students and the control group, respectively (Table 8).
Most of them (97.8\% and 91.7\%) occurred at $6000 \mathrm{~Hz}$. The portion with bilateral notching at any frequency was $4.2 \%$ and $1.5 \%$ in the music students and control group, respectively.

Generally, the music students' pure tone air-conduction thresholds were better (lower) in the frequency

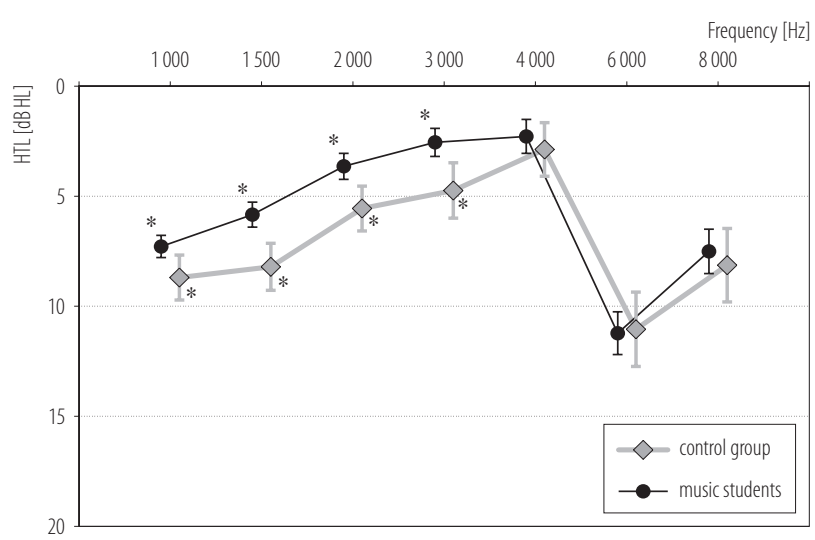

* Significant differences between the music students and the control group $(\mathrm{p}<0.05)$.

Data are given as mean values with $95 \%$ confidence intervals.

Fig. 5. Audiometric hearing threshold levels (HTL) determined in the music students ( $\mathrm{N}=168 ; 335$ ears) and in the control group $(\mathrm{N}=67 ; 134$ ears $)$ 
Table 7. Prevalence of pure tone audiometry abnormal results in the music students and in the control group

\begin{tabular}{lcc}
\hline \multicolumn{1}{c}{ Pure tone audiometry } & \multicolumn{2}{c}{$\begin{array}{c}\text { Respondents } \\
{[\%(95 \% \mathrm{CI})]}\end{array}$} \\
\cline { 2 - 3 } Hearing threshold level & music students & control group \\
$0.25-8 \mathrm{kHz}>20 \mathrm{~dB} \mathrm{HL}$ & $24.2(19.90-29.10)$ & $26.1(19.4-34.2)$ \\
$1-8 \mathrm{kHz}>20 \mathrm{~dB} \mathrm{HL}$ & $17.0(13.40-21.40)$ & $17.2(11.7-24.5)$ \\
$0.5 \mathrm{kH}, 1 \mathrm{kH}, 2 \mathrm{kH}$ and $4 \mathrm{kHz}>20 \mathrm{~dB} \mathrm{HL}$ & $8.1(5.60-11.50)$ & $6.7(3.5-12.5)$ \\
$3-6 \mathrm{kHz}>20 \mathrm{~dB}$ HL & $10.4(7.60-14.20)$ & $11.9(7.4-18.7)$ \\
Mean hearing threshold level in frequency & & $3.0(0.9-7.8)^{*}$ \\
$0.25-8 \mathrm{kHz}>20 \mathrm{~dB}$ HL & $0.3(0.01-1.90)$ & $3.0(0.9-7.8)$ \\
$1-8 \mathrm{kHz}>20 \mathrm{~dB}$ HL & $0.9(0.20-2.80)$ & $3.0(0.9-7.8)^{*}$ \\
$0.5 \mathrm{kH}, 1 \mathrm{kH}, 2 \mathrm{kH}$ and $4 \mathrm{kHz}>20 \mathrm{~dB} \mathrm{HL}$ & $0.6(0.02-2.30)$ & $3.7(1.4-8.7)$ \\
$3-6 \mathrm{kHz}>20 \mathrm{~dB} \mathrm{HL}$ & $2.1(0.90-4.40)$ & \\
\hline
\end{tabular}

$\mathrm{CI}$ - confidence interval.

* Significant differences between the music students and the control group $(\mathrm{p}<0.05)$.

Table 8. Prevalence of high-frequency notched audiograms in the music students and in the control group

\begin{tabular}{lcc}
\hline & High-frequency notching & \multicolumn{2}{c}{$\begin{array}{c}\text { Respondents } \\
\text { [\% (95\% CI)] }\end{array}$} \\
\cline { 2 - 3 } Total & music students & control group \\
\hline $6 \mathrm{kHz}$ & $13.1(9.90-17.20)$ & $8.2(4.50-14.30)$ \\
$4 \mathrm{kHz}$ & $0.3(0.01-1.90)$ & $0.7(0.01-4.20)$ \\
$4 \mathrm{kHz}$ or $6 \mathrm{kHz}$ & $13.4(10.20-17.50)$ & $9.0(5.10-15.20)$ \\
Right ear & & \\
$6 \mathrm{kHz}$ & $13.2(8.80-19.20)$ & $6.0(2.00-14.90)$ \\
$4 \mathrm{kHz}$ & $0.0(0.00-2.80)$ & $0.0(0.00-6.70)$ \\
$4 \mathrm{kHz}$ or $6 \mathrm{kHz}$ & $13.2(8.80-19.20)$ & $6.0(2.00-14.90)$ \\
Left ear & & $10.4(4.90-20.40)$ \\
$6 \mathrm{kHz}$ & $13.1(8.80-19.10)$ & $1.5(0.06-5.20)$ \\
$4 \mathrm{kHz}$ & $0.6(0.01-3.60)$ & $11.9(6.00-22.20)$ \\
$4 \mathrm{kHz}$ or $6 \mathrm{kHz}$ & $13.7(9.30-19.80)$ & \\
Bilateral notching & & $1.5(0.01-8.80)$ \\
$6 \mathrm{kHz}$ & $4.2(1.90-8.60)$ & $0.0(0.00-6.70)$ \\
$4 \mathrm{kHz}$ & $0.0(0.00-2.80)$ & $1.5(0.01-8.80)$ \\
$4 \mathrm{kHz}$ or $6 \mathrm{kHz}$ & $4.2(1.90-8.60)$ & \\
\hline
\end{tabular}

CI - confidence interval. 
range $250-3000 \mathrm{~Hz}$ (Figure 5) as compared to the control group $(\mathrm{p}<0.05)$. Furthermore, lower percentage of audiograms with speech-frequency hearing loss was observed in the musicians. However, there were no significant differences in hearing threshold levels between the students and control group in the frequency range $4000-8000 \mathrm{~Hz}$ $(p>0.05)$. Moreover, neither proportion of high-frequency losses (Table 7) nor proportion of NIHL notches in audiograms (Table 8) differed significantly in both groups.

\section{Comparison of actual and predicted hearing threshold levels}

Figure 6 presents the standardized hearing threshold levels in the music students. It is worth noting that the closer to zero value of SHTL, the better the prediction of hearing loss according to ISO 1999:2013 [22]. On the other hand, a positive value of SHTL indicates that actual hearing threshold level is higher than the predicted one, while a negative value denotes lower-than-predicted level.

As can be seen, hearing loss in the music students was higher (worse) than the one predicted (from their weekly noise exposure level) at $6000 \mathrm{~Hz}$, and lower (better) for $3000 \mathrm{~Hz}$

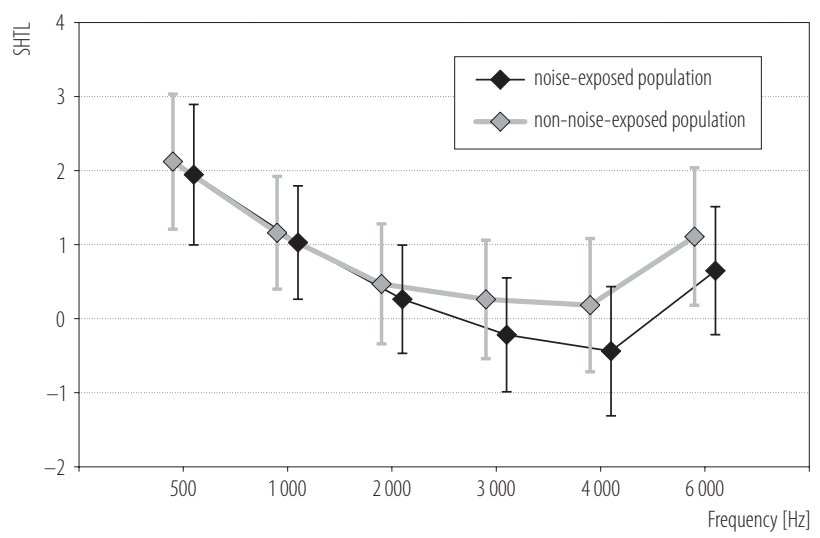

All values of SHTLs differed significantly from $0(\mathrm{p}<0.05)$.

Data are given as mean values with standard deviation.

Fig. 6. Standardized hearing threshold levels (SHTL) (relative to a reference non-noise-exposed otologically normal and noise-exposed population according to ISO 1999:2013 [22]) in the music students ( $\mathrm{N}=168 ; 335$ ears) (equations 3 and 4 )

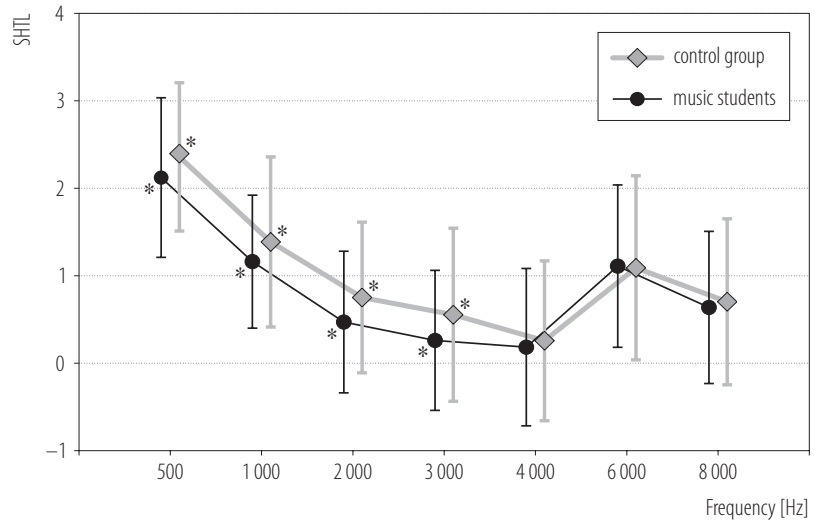

* Significant differences between the music students and the control group ( $\mathrm{p}<0.05)$.

All values of SHTLs differed significantly from $0(\mathrm{p}<0.05)$.

Data are given as mean values with standard deviation.

Fig. 7. Standardized hearing threshold levels (SHTL) (relative to a reference non-noise-exposed otologically normal population according to ISO 1999:2013 [22]) in the music students $(\mathrm{N}=168 ; 335$ ears $)$ and in the control group $(\mathrm{N}=67$; 134 ears) (equations 3 and 4 )

and $4000 \mathrm{~Hz}(\mathrm{p}<0.05)$ (Figure 6). Furthermore, the actual hearing threshold levels were significantly higher than those predicted for $500 \mathrm{~Hz}, 1000 \mathrm{~Hz}$ and $2000 \mathrm{~Hz}$. Comparison of the music students to the otologically normal (highly screened) non-noise-exposed population (database A from ISO 1999:2013 [22]) revealed that the music students' hearing losses (in the frequency range $1000-8000 \mathrm{~Hz}$ ) were higher than those expected $(p>0.05)$ (Figure 6). Similar relationships were noted when analysing hearing losses in the control group (Figure 7). Furthermore, there were no significant differences between the standardized hearing threshold levels (relative to the non-noise-exposed population) at $4000 \mathrm{~Hz}, 6000 \mathrm{~Hz}$ and $8000 \mathrm{~Hz}$ between both groups, while SHTLs in the frequency range $500-3000 \mathrm{~Hz}$ were lower in the music students compared to the control group.

\section{Association between music exposure and hearing}

Weak but statistically significant relationships were noted between audiometric hearing threshold levels in the frequency range 3000-6000 $\mathrm{Hz}$ and some of the sound 
Table 9. Relations between audiometric hearing threshold levels (HTL) and sound exposure parameters in the music students

\begin{tabular}{|c|c|c|c|c|c|}
\hline \multirow{3}{*}{$\begin{array}{c}\text { Audiometric HTL } \\
\text { frequency } \\
{[\mathrm{Hz}]}\end{array}$} & \multicolumn{5}{|c|}{ Spearman's rank correlation coefficient } \\
\hline & \multicolumn{3}{|c|}{ A-weighted equivalent continuous SPL } & \multirow{2}{*}{$\begin{array}{l}\text { weekly noise } \\
\text { exposure level }\end{array}$} & \multirow[b]{2}{*}{ noise immission level } \\
\hline & $\begin{array}{l}\text { solo and group } \\
\text { playing }\end{array}$ & group playing & solo playing & & \\
\hline 1000 & -0.032 & -0.048 & -0.002 & 0.009 & -0.005 \\
\hline 2000 & -0.011 & -0.045 & -0.019 & -0.009 & 0.024 \\
\hline 3000 & 0.043 & 0.022 & 0.072 & 0.045 & 0.129 \\
\hline 4000 & 0.046 & -0.003 & 0.135 & 0.073 & 0.066 \\
\hline 6000 & 0.002 & -0.001 & 0.115 & -0.009 & 0.080 \\
\hline 8000 & -0.070 & -0.082 & -0.053 & -0.055 & 0.054 \\
\hline
\end{tabular}

SPL - sound pressure levels.

Statistically significant correlations are given in bold.

exposure parameters (Table 9). In particular, HTLs at $4000 \mathrm{~Hz}$ and $6000 \mathrm{~Hz}$ were positively correlated with the A-weighted equivalent-continuous SPL during solo playing, while at $3000 \mathrm{~Hz}$ with noise immission level.

Furthermore, there were differences in high-frequency hearing losses between the students playing stringed,

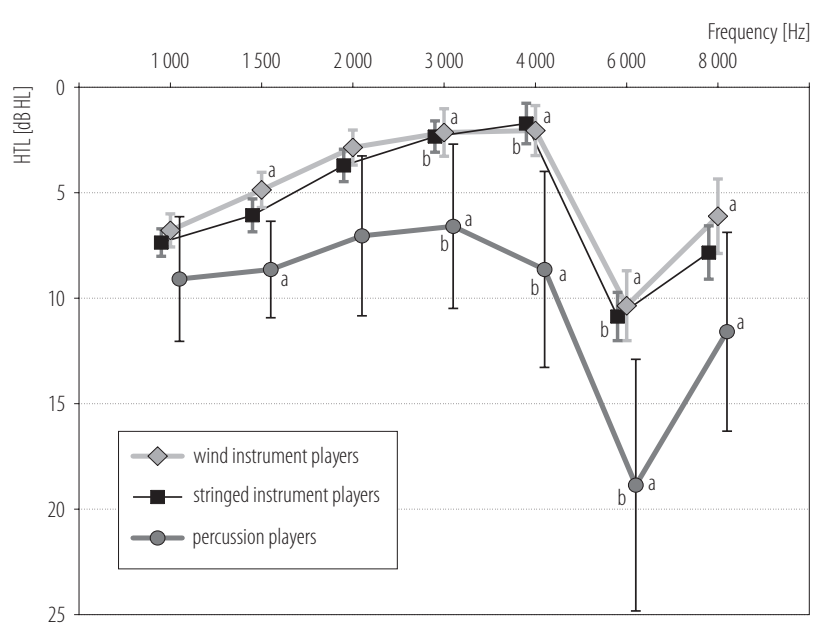

a Significant differences between the percussion and wind instrument players $(\mathrm{p}<0.05 / 3)$.

${ }^{\mathrm{b}}$ Significant differences between the percussion and stringed instrument players $(\mathrm{p}<0.05 / 3)$.

Data are given as mean values with $95 \%$ confidence intervals.

Fig. 8. Audiometric hearing threshold levels (HTL) in the music students playing stringed, wind and percussion instruments wind and percussion instruments (Figure 8). The percussion players, who were exposed to the highest $\mathrm{L}_{\mathrm{EX}, \mathrm{w}}$ levels, had significantly greater hearing losses than the lowerexposed students playing stringed and wind instruments $(\mathrm{p}<0.05 / 3)$. However, there were no significant differences between the stringed and wind instrument players. In the percussion players $(22.7 \%, 95 \%$ CI: 9.9-44\%) compared to the subjects playing stringed $(13.4 \%, 95 \%$ CI: $9.4-$ $18.9 \%)$ and wind (11.6\%, 95\% CI: 6.8-19\%) instruments the prevalence of notched audiograms was also greater; however, it was statistically insignificant (Figure 9).

Since the prevalence of high-frequency notched audiograms can vary with age, gender, noise exposure and other factors, to analyze their influence, the binary logistic regression was applied with the logistic model expressed as follows:

$$
\ln [\mathrm{p} /(1-\mathrm{p})]=\mathrm{b}_{0}+\mathrm{b}_{1} \mathrm{x}_{1}+\mathrm{b}_{2} \mathrm{x}_{2}+\ldots+\mathrm{b}_{\mathrm{n}} \mathrm{x}_{\mathrm{n}}
$$

where:

$\mathrm{p}$ - probability of the outcome, i.e., $\mathrm{x}_{1}, \mathrm{x}_{2}, \ldots, \mathrm{x}_{\mathrm{n}}$ are the independent variables included in the model (i.e., age, gender, listening to PMPs (yes/no), period of playing instrument, in years, estimated weekly noise exposure level, in $\mathrm{dB}$ ),

$\mathrm{b}_{0}, \mathrm{~b}_{1}, \ldots, \mathrm{b}_{\mathrm{n}}-$ regression coefficients (i.e., the logarithmic values of the odds ratio). 


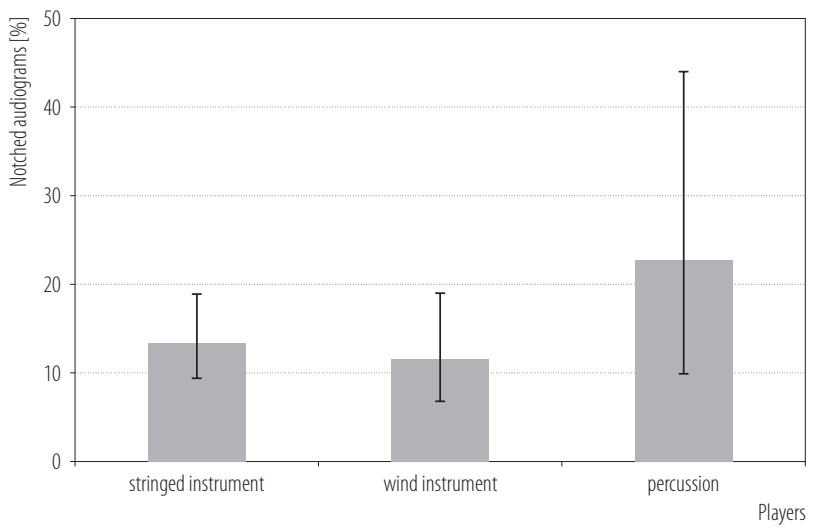

No significant differences between the pairs of subgroups of players $(\mathrm{p}>0.05 / 3)$.

Data are given as mean values with $95 \%$ confidence intervals.

Fig. 9. Prevalence of high-frequency notched audiograms in the music students playing stringed, wind and percussion instruments

An odds ratio with $95 \% \mathrm{CI}>1$ indicates a positive correlation between the dependent variable (i.e., prevalence of highfrequency notches in audiogram) and explanatory variable (e.g., age), while a value $<1$ indicates a negative correlation between the dependent variable and explanatory variable.

The binary logistic regression revealed that the prevalence of high-frequency notched audiograms was positively associated only with the students' weekly noise exposure levels $(\mathrm{OR}=1.07,95 \%$ CI: 1.014-1.13, $\mathrm{p}<0.05)$ (Table 10).
However, neither sound exposure related to music education nor frequent listening to personal music players via headphones had impact on the prevalence of tinnitus in the music students.

\section{DISSCUSION}

The study was designed to determine if classical music students are at a higher risk of hearing loss compared to non-music students and non-musicians. It also attempted to answer if hearing status of music students reflects their exposure to excessive sounds during university education.

In this study, the students' exposure was evaluated from the sound pressure levels measured during various students' activities using personal noise dosimeters and the declared time of weekly practice obtained from the questionnaire survey. It was evaluated that the music students were exposed for 10-42 h (10-90th percentile) per week to sounds at the A-weighted equivalent-continuous sound pressure level of $80-97 \mathrm{~dB}(10-90$ th percentile). Thus, about $49 \%$ and $29 \%$ of the students were exposed to sounds at weekly noise exposure level $\left(\mathrm{L}_{\mathrm{EX}, \mathrm{w}}\right)$ exceeding the upper action limit value $(85 \mathrm{~dB})$ and the exposure limit value $(87 \mathrm{~dB})$, respectively. These outcomes are similar to the results of earlier studies both, those

Table 10. Association between high-frequency notched audiograms or tinnitus in the music students (dependent binary variable) and weekly noise exposure level and other individual factors (independent variables) tested using the logistic regression

\begin{tabular}{|c|c|c|c|c|}
\hline \multirow{2}{*}{ Variable } & \multicolumn{2}{|c|}{ Notched audiogram $^{\mathrm{a}}$} & \multicolumn{2}{|l|}{ Tinnitus $^{b}$} \\
\hline & OR $(95 \% \mathrm{CI})$ & $\mathrm{p}$ & OR $(95 \% \mathrm{CI})$ & $\mathrm{p}$ \\
\hline Age & $0.851(0.719-1.007)$ & 0.061 & $0.936(0.742-1.182)$ & 0.579 \\
\hline Gender & $0.579(0.279-1.204)$ & 0.143 & $1.405(0.489-4.033)$ & 0.525 \\
\hline Listening to PMP & $2.069(0.598-7.165)$ & 0.250 & $1.242(0.435-3.542)$ & 0.684 \\
\hline Period of playing instrument & $1.098(0.989-1.220)$ & 0.081 & $1.072(0.924-1.244)$ & 0.359 \\
\hline Weekly noise exposure level & $1.070(1.014-1.130)$ & 0.014 & $0.961(0.877-1.054)$ & 0.401 \\
\hline
\end{tabular}

PMP - personal media player; OR - odds ratio; CI - confidence interval.

${ }^{\text {a }} \mathrm{Chi}^{2}=12.798, \mathrm{df}=5, \mathrm{p}=0.0253641$.

${ }^{\mathrm{b}} \mathrm{Chi}^{2}=2.215, \mathrm{df}=5, \mathrm{p}=0.8186489$.

Statistically significant association is given in bold. 
concerning young musicians and professional orchestral musicians [13-17].

In this study, pure-tone air-conduction thresholds and hearing-related symptoms in the classical music students were compared to the control group. Since HTLs of the study subjects were also compared to the age-related reference data from highly screened otologically normal persons (database A from ISO 1999:2013), the control group comprised "normal" (unscreened) young people, mainly non-music students, among whom about one-quarter were occasionally exposed to noise during internship or apprenticeship. Generally, there were no significant differences between the music students and the control group in terms of age, gender, medical history, physical features and some aspects of lifestyle such as a noisy hobby. However, greater fractions of the music students frequently listened to personal media players, while greater proportion of the subjects in the control group often used noisy tools in the past.

Individual susceptibility (or vulnerability) to noise, along with the degree of hearing loss, varies greatly among people. It is believed that NIHL is a complex disease resulting from interaction between intrinsic and environmental factors. Besides, well-known environmental factors contributing to NIHL, such as exposure to noise and some other factors, may also play a role. They include co-exposures to ototoxic substances (organic solvents and heavy metals), co-exposure to noise and vibration, ototoxic drugs (aminoglycosides) and heat. Associations have also been observed between several individual factors and NIHL, including: smoking, elevated blood pressure, diabetes, cholesterol levels, skin pigmentation, gender and age, and genetic predisposition as suggested by clinical knowledge and guidelines [28].

Additional NIHL risk factors were rare in both groups of the subjects. Furthermore, there were no significant differences between the music students and the comparative group concerning the prevalence of smoking, elevated blood pressure, diabetes, white-finger syndrome, light skin pigmentation, ototoxic antibiotic treatments and overweight $(\mathrm{BMI}>25)$.

Hearing loss is a permanent threshold shift exceeding a predefined limit. The limit value has not been standardized so far. In this study, the hearing thresholds up to $20 \mathrm{~dB}$ HL were considered as normal since some studies of NIHL prevalence in adults have defined NIHL in terms of absolute thresholds levels above $20 \mathrm{~dB}$ HL [29]. Thus, majority of the music students and control subjects were found as having normal hearing because in both groups in the case of $83 \%$ of ears HTLs (in the frequency range $1000-8000 \mathrm{~Hz}$ ) did not exceed $20 \mathrm{~dB} \mathrm{HL}$.

Only a few of them had high-frequency hearing loss (in the frequency range of $3000-6000 \mathrm{~Hz}$ ) greater than $20 \mathrm{~dB}$ HL, but there were no significant differences in the proportion of abnormal audiograms between the groups. However, the music students' pure-tone air-conduction thresholds were better in the frequency range $250-3000 \mathrm{~Hz}$ as compared to the control group, while no significant differences were observed in a higher frequency range $(4000-8000 \mathrm{~Hz})$.

Comparison of the music students and control subjects to the highly screened otologically normal non-noiseexposed population (database A from ISO 1999:2013) revealed that their hearing losses (in the frequency range of $1000-8000 \mathrm{~Hz}$ ) were higher than those expected (Figure 7). Moreover, there were no significant differences between the standardized hearing threshold levels (relative to the non-noise-exposed population) at $4000 \mathrm{~Hz}, 6000 \mathrm{~Hz}$ and $8000 \mathrm{~Hz}$ between both groups, while SHTLs in the frequency range of 500-3000 Hz were lower in the music students compared to the control group, i.e., closer to hearing threshold levels in the highly screened otologically normal non-noise-exposed population.

Furthermore, actual hearing loss in the music students was significantly higher (worse) than that predicted from the sound exposure level (according to ISO 1999:2013) 
at $6000 \mathrm{~Hz}$, and lower (better) at $3000 \mathrm{~Hz}$ and $4000 \mathrm{~Hz}$ (Figure 6).

Recently, Lüders et al. [30] have analyzed hearing threshold levels 250-16 $000 \mathrm{~Hz}$ in a group of 42 music students in comparison to a non-musician group in order to determine whether high-frequency audiometry is a useful tool in early detection of hearing impairment. When tested using conventional audiometry, likewise in our study, majority of the subjects (92.9\%) had hearing thresholds within normal limits. However, contrary to our results, both conventional and high-frequency audiometry revealed statistically significant differences when comparing the audiometric thresholds of the music students group and control group, with the worst threshold noted in the group of music students. The most significant differences were found in the evaluation of high frequencies, which allows for the inference that sporadic high-frequency threshold assessment can be useful in early detection of hearing loss in musicians.

Since in our study majority of the subjects had hearing thresholds within normal limits, in order to identify early signs of NIHL, the prevalence of high-frequency notches (i.e., a sharp drop in the hearing sensitivity at $4000 \mathrm{~Hz}$ or $6000 \mathrm{~Hz}$ ) in audiograms was analyzed.

In our study, high-frequency notches (mainly at $6000 \mathrm{~Hz}$ ) were found in $13.4 \%$ and $9 \%$ of audiograms in the musicians and non-musicians, respectively. Moreover, no significant differences were noted between both groups.

The prevalence of notches at $6000 \mathrm{~Hz}$ in the control group is not surprising since according to the Nord-Trøndelag Hearing Loss Study [31] such notches were observed both in unscreened and screened for a history of noise exposure and ear-related disorders and diseases populations of men and women up to 40 years old. Moreover, some earlier studies in musicians, including professional orchestral musician, have also shown high frequency notches (mainly at $6000 \mathrm{~Hz}$ ) in audiograms [7,9,10]. Similar outcomes have been also obtained for younger (student) musicians $[18,19]$.
For example, Phillips et al. [19] have analyzed hearing capability in music students $(\mathrm{N}=329)$ and found typical NIHL notches in $45 \%$ of them, with $78 \%$ of notches occurring at $6000 \mathrm{~Hz}$. Proportion of the total population with bilateral notching at any frequency was $11.5 \%$, mostly occurring at $6000 \mathrm{~Hz}$. There was a significant increase in the frequency of notching in students who reported more than $2 \mathrm{~h}$ /day of personal practice. However, no significant associations were observed for instrument group or other noise exposures.

Generally, various definitions of NIHL notches are applied. Notches were conservatively defined (from clinical standpoint) as at least a $10 \mathrm{~dB}$ drop in the threshold from $1000 \mathrm{~Hz}, 2000 \mathrm{~Hz}$, or $3000 \mathrm{~Hz}$ to $4000 \mathrm{~Hz}$ or from $1000 \mathrm{~Hz}, 2000 \mathrm{~Hz}, 3000 \mathrm{~Hz}$, or $4000 \mathrm{~Hz}$ to $6000 \mathrm{~Hz}$, with at least a $5 \mathrm{~dB}$ recovery at $8000 \mathrm{~Hz}$. In the aforesaid study, notches were defined as at least a $15 \mathrm{~dB}$ drop at $4000 \mathrm{~Hz}$ or $6000 \mathrm{~Hz}$ relative to the best preceding frequencies back to $1000 \mathrm{~Hz}$ [19].

On the other hand, in this study we analyzed the presence of notches at least of $15 \mathrm{~dB}$ depth relative to both the best preceding threshold from $1000 \mathrm{~Hz}$, and the threshold at a $8000 \mathrm{~Hz}$. Thus, it is not surprising that we found a smaller percentage of notched audiograms compared to the earlier observations (13\% vs. $45 \%$ ) [19].

Nevertheless, in this study the odds ratio of notching in the music students increased significantly along with a higher weekly noise exposure level $(\mathrm{OR}=1.07,95 \%$ CI: 1.014-1.13, $\mathrm{p}<0.05)$. When applying less severe criteria, the proportion of notched audiograms increased to $22.7 \%$, but the association between music exposure and their incidence was no longer valid.

It is worth noting that there were differences (but not statistically significant) in the prevalence of high-frequency notched audiograms among the young musicians playing stringed, wind and percussion instruments. The highest incidence of notches was observed in the percussion players, who were exposed to the highest $\mathrm{L}_{\mathrm{EX}, \mathrm{W}}$ levels. 
The percussion players had also significantly greater hearing losses than the lower-exposed students playing stringed and wind instruments. However, there were no significant differences between the stringed and wind instruments players (Figure 8 and 9).

Regarding hearing ability assessed using the (m)AIADH, the prevalence of slight deficits was also the highest in the subjects playing percussion (Table 6). In particular, significantly higher proportions of the students playing percussion than those playing stringed or wind instruments scored relatively low in subscales evaluating intelligibility in noise and quiet. But generally, both the music students and the control subjects obtained a mean total score in the (m)AIADH, suggesting no substantial hearing problems. Moreover, neither significant differences in the total score nor in the scores in various subscales were noted between the aforesaid groups (Table 5).

However, according to a subjective evaluation, greater proportions of the music students, compared to the control group, reported hearing-related symptoms, in particular hyperacusis and constant or temporary tinnitus.

Please note that in this study the prevalence of tinnitus was analyzed independently of prior exposure to noise. Moreover, neither sound exposure due to music education nor frequent listening to personal music players had impact on the prevalence of tinnitus in the music students. For comparison, earlier Miller et al. [32] have analyzed the incidence of tinnitus after exposure to loud music in student musicians. In their study, tinnitus was reported by $63 \%$ of 27 music students.

In our study, music students were not being taught that music was a sound source capable of harming hearing. They were also unaware of, and unprepared to recognize and manage risk resulting from excessive sound exposures. Thus, it is not surprising that only $8.9 \%$ of the music students reported using hearing protective devices at present or in the past, while $47 \%$ of them intended to use them in the future.
In the study quoted above [32], majority of the students $(74 \%)$ reported having been taught about the effects of noise on hearing and health; however, less than a third used ear protection while playing their instruments, and those who did, used it inconsistently. Thus, education is needed to encourage consistent use of hearing protective devices while playing an instrument. In addition, comprehensive hearing conservation programs for music students should include sound level monitoring and annual audiometry.

\section{CONCLUSIONS}

This study confirmed that classical music students, likewise professional orchestral musicians, are often exposed to music (sound) at levels exceeding the upper exposure action values from the Noise Directive 2003/10/EC [11]. Majority of the music students in this study had pure-tone air-conduction hearing thresholds within normal limits. Furthermore, their hearing threshold levels in the frequency range $4000-8000 \mathrm{~Hz}$ did not differ significantly from those of the control group, comprising non-music students and non-musicians, not occupationally exposed to noise.

Comparison of the music students to the highly screened otologically normal non-noise-exposed population revealed that their hearing losses in the frequency range $500-8000 \mathrm{~Hz}$ were higher than those expected. Furthermore, actual hearing loss in the music students was significantly higher (worse) than that predicted according to ISO 1999:2013 [22] based on their exposure to music at $6000 \mathrm{~Hz}$, and lower (better) at $3000 \mathrm{~Hz}$ and $4000 \mathrm{~Hz}$.

Nevertheless, high frequency notched audiograms, typical of noise-induced hearing loss, were found in $13.4 \%$ of the music students. The odds ratio of notching increased significantly along with a higher A-weighted weekly noise exposure level associated with the music education.

To sum up, our findings suggest that classical music students are at an increased risk of NIHL and confirm the need to include them in a hearing conservation program. 


\section{REFERENCES}

1. Axelsson A, Lindgren F. Hearing in classical musicians. Acta Otolaryngol Suppl. 1981;377:3-74, https://doi.org/10.3109/ 00016488109108191.

2. Karlsson K, Lundquist PG, Olaussen T. The hearing of symphony orchestra musicians. Scand Audiol. 1983;12(4): 257-64, https://doi.org/10.3109/01050398309044429.

3. Royster JD, Royster LH, Killion MC. Sound exposures and hearing thresholds of symphony orchestra musicians. J Acoust Soc Am. 1991;89(6):2793-803, https://doi.org/10.1121/1.400719.

4. Obeling L, Poulsen T. Hearing ability in Danish symphony orchestra musicians. Noise Health. 1999;1(2):43-9.

5. Kähäri KR, Axelsson A, Hellström PA, Zachau G. Hearing development in classical orchestral musicians. A followup study. Scand Audiol. 2001;30(3):141-9, https://doi.org/ 10.1080/010503901316914511.

6. Emmerich E, Rudel L, Richter F. Is the audiologic status of professional musicians a reflection of the noise exposure in classical orchestral music? Eur Arch Otorhinolaryngol. 2008; 265(7):753-8, https://doi.org/10.1007/s00405-007-0538-z.

7. Jansen EJ, Helleman HW, Dreschler WA, de Laat JA. Noise induced hearing loss and other hearing complaints among musicians of symphony orchestras. Int Arch Occup Environ Health. 2009;82(2):153-64, https://doi.org/10.1007/s00420008-0317-1.

8. Zhao F, Manchaiah VK, French D, Price SM. Music exposure and hearing disorders: An overview. Int J Audiol. 2010;49(1): 54-64, https://doi.org/10.3109/14992020903202520.

9. Toppila E, Koskinen H, Pyykkö I. Hearing loss among classical-orchestra musicians. Noise Health. 2011;13(50):45-50, https://doi.org/10.4103/1463-1741.74001.

10. Pawlaczyk-Łuszczyńska M, Zamojska M, Dudarewicz A, Zaborowski K. Noise-induced hearing loss in professional orchestral musicians. Arch Acoust. 2013;32(2):223-34, https:// doi.org/10.2478/aoa-2013-0027.

11. Directive 2003/10/EC of European Parliament and of the Council of 6 February 2003 on the minimum health and safety requirements regarding the exposure of workers to the risks arising from physical agents (noise) (17th individual Directive within the meaning of Article 16(1) of Directive 89/391/EEC). Off J Eur Union L 42/38, p. 38-44 (Feb 15, 2003).

12. [The Decree issued by the Minster of Labor and Social Policy of June 23, 2014 on maximum admissible concentration and maximum admissible intensity values for agents harmful to human health in the work environment. J Laws 2014, No. 0, item 817]. Polish.

13. Phillips SL, Mace S. Sound level measurements in music practice rooms. Music Perform Res. 2008;2:36-47.

14. Laitinen HM, Toppila EM, Olkinuora PS, Kuisma K. Sound exposure among the Finnish National Opera personnel. Appl Occup Environ Hyg. 2003;18(3):177-82, https://doi. org/10.1080/10473220301356.

15. O'Brien I, Wilson W, Bradley A. Nature of orchestral noise. J Acoust Soc Am. 2008 Aug;124(2):926-39, https://doi. org/10.1121/1.2940589.

16. Schmidt JH, Pedersen ER, Juhl PM, Christensen-Dalsgaard J, Andersen TD, Poulsen T, et al. Sound exposure of symphony orchestra musicians. Ann Occup Hyg. 2011;55(8): 893-905, https://doi.org/10.1093/annhyg/mer055.

17. Pawlaczyk-Łuszczyńska M, Dudarewicz A, Zamojska M, Śliwinska-Kowalska M. Evaluation of sound exposure and risk of hearing impairment in orchestral musicians. Int J Occup Saf Ergon. 2011;17(3):255-69, https://doi.org/10. 1080/10803548.2011.11076892.

18. Fearn RW. Hearing loss in musicians. J Sound Vib. 1993; 163(2):372-8, https://doi.org/10.1006/jsvi.1993.1174.

19. Phillips SL, Henrich VC, Mace ST. Prevalence of noise-induced hearing loss in student musicians. Int J Audiol. 2010;49(4): 309-16, https://doi.org/10.3109/14992020903470809.

20. Barlow C. Evidence of noise-induced hearing loss in young people studying popular music. Med Probl Perform Art. 2011;26(2):96-101.

21. Mansfield JD, Baghurst PA, Newton VE. Otoacoustic emissions in 28 young adults exposed to amplified music. Br J Audiol. 1999;33(4):211-22, https://doi.org/10.3109/ 03005369909090102. 
22. ISO 1999:2013. Acoustics - Estimation of noise-induced hearing loss. Geneva: International Organization for Standardization; 2013.

23. ISO 7029:2000. Acoustics - Statistical distribution of hearing thresholds as a function of age. Geneva: International Organization for Standardization; 2000.

24. Meijer AG, Wit HP, Tenvergert EM, Albers FW, Muller Kobold JE. Reliability and validity of the (modified) Amsterdam Inventory for Auditory Disability and Handicap. Int J Audiol. 2003;42(4):220-6, https://doi.org/10.3109/ 14992020309101317.

25. PN-N-01307:1994. [Noise. Permissible values of noise in the workplace. Requirements relating to measurements]. Warszawa: Polish Committee for Standardization; 1994. Polish.

26. ISO 9612:2009. Acoustics - Determination of occupational noise exposure - Engineering method. Geneva: International Organization for Standardization; 2009.

27. PN-EN ISO 9612:2011. [Acoustics - Determination of occupational noise exposure - Engineering method]. Warszawa: Polish Committee for Standardization; 2011. Polish.

28. Śliwińska-Kowalska M, Dudarewicz A, Kotyło P, Zamysłowska-Szmytke E, Pawlaczyk-Łuszczyńska M, Gajda-Szad- kowska A. Individual susceptibility to noise-induced hearing loss: Choosing an optimal method of retrospective classification of workers into noise-susceptible and noise-resistant groups. Int J Occup Med Environ Health. 2006;19(4): 235-45, https://doi.org/10.2478/v10001-006-0029-2.

29. Agraval Y, Platz EA, Niparko JA. Prevalence of hearing loss and differences by demographic characteristics among US adults: Data from the National Health and Nutrition Examination Survey, 1999-2004. Arch Intern Med. 2008;168: 1522-30, https://doi.org/10.1001/archinte.168.14.1522.

30. Lüders D, Gonçalves CG, Lacerda AB, Ribas Â, de Conto J. Music students: Conventional hearing thresholds and at high frequencies. Braz J Otorhinolaryngol. 2014;80(4):296-304, https://doi.org/10.1016/j.bjorl.2014.05.010.

31. Engdhal B, Tambs K, Borchgrevink HM, Howard HJ. Screened and unscreened hearing threshold levels for the adult population: Results from the Nord-Trøndelag Hearing Loss Study. Int J Audiol. 2005;44(4):213-30, https://doi. org/10.1080/14992020500057731.

32. Miller VL, Stewart M, Lehman M. Noise exposure levels for student musicians. Med Probl Perform Art. 2007;22(4): $160-5$.

This work is available in Open Access model and licensed under a Creative Commons Attribution-NonCommercial 3.0 Poland License - http://creativecommons.org/ licenses/by-nc/3.0/pl/deed.en. 